\title{
Dosvox Usability: recommendations for improving interaction of blind people with the web using the system
}

\author{
Edson Rufino de Souza ${ }^{\mathrm{a}, \mathrm{b}^{*}}$ and Sydney Fernandes de Freitas ${ }^{\mathrm{b*}}$ \\ ${ }^{a}$ Nacional Institute of Industrial Property, Praça Mauá 7, Centro, Rio de Janeiro, Brasil \\ ${ }^{\mathrm{b}}$ PPDESIGN, ESDI/UERJ, Rua Evaristo da Veiga, 95, Centro, Rio de Janeiro, Brasil
}

\begin{abstract}
At present, it is recognized that the Internet plays key role in universalization of opportunities in society in which we live. For people with disabilities, the content must be accessible in all websites, but the assistive technologies used must be adequate to the specific needs of people with disabilities. Dosvox is a free system developed in the Universidade Federal do Rio de Janeiro (UFRJ) specially designed for blind people and used by them in the performance of their tasks with the use of computers. Previously, through exploratory research based on the observation of the interaction of blind students with the Web, usability problems were identified in the Dosvox interface and in the Webvox, the Web browser included in the system, and these problems were related to the fact that the interface is designed in accordance with the mental model of these Information Technology professionals. This study consolidate the problems in earlier phases of the research, link the results with usability heuristics of Nielsen and propose several improvements to Dosvox and its development process.
\end{abstract}

Keywords: blind people, usability, accessibility, interaction design, redesign

\section{Introduction}

At present, it is recognized that the Internet plays key role in universalization of opportunities in society in which we live. For people with disabilities face a physical world unsuited to their needs, the resources brought by the advent of the Internet opened up new paradigms: blind people may make purchases on e-commerce sites, people with low vision may read online newspapers in which we can enlarge the text size on screen, deaf people may read text from video subtitles.

However, most web sites is not adequate to good practice in accessibility [9], making it difficult for these opportunities become a reality. Some studies say that blind people face the major difficulties in accessing the web due to lack of proper accessibility [7][8]. An assistive technology used by blind people must be adequate to their needs, or it will be another barrier to access of blind people to the Web. This study continues a research that has investigate the usability of Dosvox, a system designed to blind people.

In the next sections, we will present a literature review about these topics, a review of earlier phases of the research and, finaly, present the methodology, results and conclusions.

\section{Literature review}

\subsection{About blindness}

In Brazil, in the legislative sphere, the Federal Decree 5296 (2004) defines impaired vision in two levels: "blindness, in which visual acuity is equal to or less than 0.05 in the better eye with best optical correction; low vision, which means visual acuity between 0.3 and 0.05 in the better eye with best optical correction, in which case the sum of the measure of

* Corresponding author. E-mail: edson.rufino@gmail.com

**_Corresponding author. E-mail: sydneyfreitas@terra.com.br 
the visual field in both eyes is equal to or less than 60 degrees, or the simultaneous occurrence of any of the above conditions".

Under this classification, people with up to $5 \%$ of their vision are blind; and that have visual acuity between $5 \%$ and $30 \%$ characterizes the so-called low vision, which is not classified as blindness.

Another type of classification can be found on the website of the Institute Benjamin Constant (IBC), which is considered blind individuals whose vision, even with adequate correction in the better eye, is up to $20 / 200$ (or 6/60 ). In other words, if a person can only see at 20 feet (about $6 \mathrm{~m}$ ) or less what a person with normal vision can see at 200 feet (about $60 \mathrm{~m}$ ).

\subsection{Ergonomics and human-computer interaction}

It is understood that the ergonomics of the approach is a facilitator between man and technology, providing technical and grant to adapt the work to human beings [1]. In this study, we intend to allow the blind to improve the relationship with the use of computers through Dosvox in a ergonomic perspective.

In this perspective, applied to the ergonomics and human-computer interaction, it is very important the observation of blind people on the performance of their tasks using Dosvox to access the Web to observe real problems and thus propose improvements to the system analyzed.

\subsection{Usability and accessibility}

Usability can be defined in accordance with ISO 9241-11, as effectiveness, efficiency and satisfaction in a given context of use by specific users [3].

ISO 16071 [2], which sets international guidelines for the accessibility of human-computer interfaces, conceptually defines accessibility as the "usability of a product, service, environment or resource by people with the broadest range of capabilities" (physical, cognitive and perceptual abilities).

Thus, it is correct to say that accessibility is the combination of effectiveness, efficiency and satisfaction by anyone and without defining a specific context of use.

\subsubsection{Web accessibility}

A Web document will be read by an assistive technology from the way Web pages are structured using markup languages, like HTML and XHTML.
Documents must be built to ensure maximum understanding, regardless of how it will be accessed, either in a visual, audible or tactile maneer, ensuring accessibility for different input and output devices.

As the vast majority of blind people access the computer using keyboard, all the sections and links on a page must be capable of being easily accessed by this device. These people may take three times longer to perform a task [8].

\subsection{Assistive technologies}

Assistive technology is physical devices or software used by people with disabilities to fulfill their tasks [2].

This technology works by extending the possibilities of their perceptual and motor users. You can point to as examples of these technologies: prosthetic devices for people with motor disabilities, hearing aids for people with moderate deafness and software like screen magnifiers for people with low vision.

Assistive technologies are often designed with public and specific tasks, such as the system Dosvox. With the definition of specific context of use and type of users, the focus in the design cycle of these products is on usability, and not in accessibility. However, it is important to note that these tools have direct influence on the overall accessibility level of Web access by the blind.

There are many assistive technologies that support blind people access to electronic sites on the Web There are computer programs from the physical devices. In this study, the focus is only on assistive technologies based on computer programs.

Blind people mainly use assistive technologies based on computer programs that use speech synthesis to access the computer and the internet. Screen readers and Dosvox system are among the programs in this category.

Basically, the screen readers make an interface between the blind and programs on your computer, turning the content that is focused on the screen in synthesized voice, liable to be understood by hearing for people who can not see or have difficulty in having access to visual information, such as people with low vision or cognitive disabilities. There are many screen readers available, but most of them are commercial and too expensive. Some examples of screen readers are Jaws, Virtual Vision and NVDA (this last is free and open source software).

The Dosvox system is a computer system for use of the PC that communicates with the user via speech 
synthesis in Portuguese (which can be configured in other languages). It consists of a set of programs that make up an integrated environment for use by blind people. Among the resources that accompany Dosvox currently include the following:

- Operating system that contains the elements of user interface;

- System own speech synthesis, which translates into all voice messages displayed by the system;

- Editor, reader, printer and text formats in conventional format or Braille;

- Programs for Internet access, such as electronic mail (Cartavox) and Web browser (Webvox) and

- Games didactic and playful, among others.

Dosvox differs from screen readers for being an independent environment with their own applications. Screen readers work as an interface between the programs installed on the machine and users.

According to NCE-UFRJ lab, the system was designed with the objective of allowing the execution of tasks by non-technical users. For example, many of the sound messages issued by Dosvox are recorded human voice, which, according to its developers, reduces the rate of stress for the user.

The system is free, and it runs from MS Windows, and includes free support via mailing lists and phone. Dosvox system is widely used in Brazil, and possibly is the most used as assistive technology for blind people. Moreover, it is an open source solution, and subject to proposed improvements by the community.

\section{Earlier stages of research}

\subsection{Exploratory research: cooperative evaluation}

To observe the influence of the characteristics of Dosvox in the Web access by blind people, an exploratory survey was conducted with blind students.

The volunteers were selected through exploratory interviews with eight students with impaired vision (four blind students and four blind students with low vision). Among the blind students, it was realized that two were more interested and experienced in the use of Dosvox. These students participated in a cooperative evaluation, to be observed the influence of the characteristics of Dosvox as Web access for blind people [4].

\subsubsection{Results of exploratory research}

The vast majority of problems encountered by the volunteers during the study was due to the low level of accessibility of electronic sites visited (except the site of Dosvox, related to one of the proposed tasks). However, we noticed some problems of access provided by Dosvox. For one of the volunteers, less frequent user of the program in relation to the other voluntary, some terms used in Dosvox menus were not easy to understand and needed explanation (even though she knew the program for over ten years), as the "Trazer página" (or bring page) and "Gerador de homepages" (or homepages generator).

There were some cases where links have been activated the option "Páginas selecionadas" (selected pages, option S) and the page was not opened, probably because some defect in the program. Moreover, it was not understandable during the interaction in a Web page too the difference between plain text and links, and also barely noticeable difference between these and the titles and subtitles of the pages, according to volunteers. Overall, the program was praised for being considered easy to learn and be free.

From these results, we have listed possible causes for the problems encountered. Among them, it was thought that there could have been the influence of the mental model of Dosvox developers, IT professionals, on the existence of diagnosed usability problems.

\subsection{Interviews with the developers of Dosvox}

Was also carried out a structured interview with the developers of the program Dosvox. The goal of this step was to observe the specific influence of these people in the mental model of usability problems found in the interface Dosvox ([5]). All members of the development team Dosvox agreed to participate in the survey through the Term of Informed Consent.

\subsubsection{Interviews results}

The interviews confirmed that the mental model developers influenced the existence of usability problems, since:

- the terms used in the interface of the system are chosen by the developers, without prior consultation with users, and technical constraints also influence the choice of terms, like if the initial term of one to be chosen is already being used, they try to use another term;

- the maneer how the elements of a Web page are presented with the use of distinctive sounds is con- 
sidered good for developers, but was confused by the participants in the exploratory research; and

- usability assessments with or without users are not normally performed by developers.

\subsection{Study with blind experts in accessibility}

Based on the results of the previous steps, we performed a third stage of the research: a study of two blind people who are experts in web accessibility and very experienced in the use of assistive technologies based on speech synthesis, as Dosvox [6].

This phase of the research was defined by the observation of the two blind experts in their interaction with the Web via Dosvox through individual cooperative evaluations, as it was done in exploratory research. This step was intended to provide a user experience that allows experts to form a more concrete opinion about the system, since they usually do not use the Dosvox system to access the Web.

After the cooperative evaluations, it was applied structured interviews using open questions. The interview has covered the following aspects: Dosvox menu as a interface solution; opinion of them about the pros and cons of Webvox; assistive technology that they use more, and suggestions for improvements to the system.

At this stage, we could get information from theoretical and practical, as it united the Web accessibility knowledge of experts, their familiarity with various assistive technologies based on computer programs that use speech synthesis and its personal experience with problems of interaction provided by a Web inaccessible to the blind.

\subsubsection{Results of study with blind specialists in accessibility}

In the cooperative evaluations, as expected, the experts perform the proposed tasks were much easier to than students participating in the exploratory research (the tasks were the same in the two phases). Some difficulties were also provided by problems of accessibility of electronic sites accessed in the tasks.

In this phase, there were also problems caused by differences between the mechanisms of interaction between the Webvox and Jaws, screen reader that both voluntary use in their daily lives. It was possible to perceive that this familiarity with Jaws also influenced their choices of suggestions for improvement of the Dosvox system.

One of the major accessibility problems was the impossibility of use of internal search of the website
Submarino. This resource relies on Javascript, that was not supported in Webvox and older web browsers, and over a few pages of links before the search box, which they say is their main navigation feature in their interactions with websites.

In the interview, the Dosvox menu has been praised as a good interface solution, with the proviso that it should become similar to the pattern of interaction of Windows (shortcut keys, for example). Among the issues cited as positive in Dosvox system and Webvox, they include:

- the fact that Dosvox is a free system;

- the processing and presentation of form controls, which makes them more intelligible;

- the integration of the Dosvox system with the browser;

- Dosvox be an environment more friendly to those just starting out in IT;

- the ease of use of browser functions, and speed in loading pages.

Among the negative aspects were highlighted:

- the quest text does not record the words used in the last search performed;

- the browser requires that the user choose one option in a form to continue the navigation, and it is not obvious to skip;

- there is no visual presentation of pages, which hinders the understanding of a web page to a person who can see;

- the difference between the interaction patterns used in Dosvox and Windows;

- the lack of adequate description of the elements of the pages viewed, which is made with sound; and

- lack of support for JavaScript and other technologies.

Also, they were asked to propose suggestions for improvements to the Webvox, and they proposed the following changes:

- the help system could be navigable and interactive;

- there be a keyboard command to find form fields in a page;

- the possibility of recognition of repetitive headers, which could be skipped;

- it is desirable that the shortcut keys be similar to those of Windows;

- there could be an alert message when you can not use something because it is dependent on Javascript;

- HTML elements such as lists and headers could be recognized and used in navigation inside a page;

- there be literal description of the elements of a page instead of using only incidental sounds; 
- transform Webvox/Dosvox in a system that is not only used by the blind, but by anyone, including the layout of the pages; and

- there be a version of Webvox independent of Dosvox for use in accessibility tests and assessments.

\section{Methodology}

This is a complementary phase of the research, and in this study we propose to consolidate the problems discovered by the earlier phases and to generate improvement recommendations.

We have linked the problems with usability heuristics of Jakob Nielsen [10], to better understanding of the problem and easier proposition of recommendations:

1. Visibility of system status

2. Match between system and the real world

3. User control and freedom

4. Consistency and standards

5. Error prevention

6. Recognition rather than recall

7. Flexibility and efficiency of use

8. Aesthetic and minimalist design

9. Help users recognize, diagnose, and recover from errors

10. Help and documentation

Below we present the problems with heuristics violated and improvement recommendation:

- Use of terms in menus not easily understandable by the users

heuristics violated: $2,5,6$

recommendation: realize a card sorting with user participation to define a new and adequate taxonomy to be used in the Dosvox and Webvox menus;

- Lack of consistency between Dosvox and Windows shortcuts and interaction patterns heuristics violated: 4,5

recommendation: where be possible, use patterns from Windows.

- Help system does not record the last words used in the last search performed

heuristics: $5,7,10$

recommendation: the help system could be navigable and interactive, to facilitate the support.

- Webvox requires that the user choose one option in a form to continue the navigation, and it is not obvious to skip

heuristics: 3, 4, 6

recommendation: there be keyboard commands to find and skip form fields in a page.

- Visual presentation in Dosvox is totally different of the traditional Web browsers, and this make the Webvox an browser only for blinds heuristics: 4

recommendation: the visual presentation can be added to Dosvox/Webvox, keeping the same interaction patterns, like Dosvox menus. This can transform Webvox/Dosvox in a system that is not only used by the blind, but by anyone, including the layout of the pages.

- Difficulty of understanding of the concepts presented by incidental sounds during the Web navigation by Webvox

heuristics: 2, 4, 5, 6

recommendation: keep sounds but add subsequent and adequate literal description of each type of element of the pages viewed.

- Lack of support for JavaScript and other technologies

heuristics: 3, 7

recommendation: if the technologies can not be supported in the future, there could be an alert message when you can not use something because it is dependent on Javascript.

- lack of possibility of navigation between HTML elements to accelerate interaction heuristics: 3,7

recommendation: the possibility of recognition of repetitive headers, which could be skipped, and recognition of HTML elements such as lists and headers to be used in navigation inside a page.

\section{Conclusions}

The categorization of issues in relation to usability principles violated by them allowed a better understanding of each problem, and easier to propose suggestions for improvements to each of them.

It can be seen as well the importance of a cyclical process of reviewing the results of research on usability, since the iterative process allows to reach a more complete achievement of the objectives and needs of users.

As developments, it is proposed that studies are carried out with users to define a new taxonomy for Webvox and Dosvox. It is also important that the process of developing the system Dosvox can be reviewed in relation to good practice in user-centered design, which will facilitate their gradual and steady improvement for the good of its large population of Portuguese-speaking blind users. 


\section{References}

[1] C. Mont'alvão and A. Moraes, Ergonomia: Conceitos e Aplicações, 2AB, 2003.

[2] ISO - International Organization of Standardization (2003). ISO/TS 16071: Ergonomics of human-system interaction Guidance on accessibility for human-computer interfaces. Geneva, Switzerland.

[3] P. Jordan, An Introduction To Usability. CRC, 1998.

[4] E. R. Souza, S. F. Freitas, Avaliação cooperativa de sítios eletrônicos com pessoas cegas. In: Proceedings of CIPED 2007. Rio de Janeiro: 2007. On-line. Available in: $<$ http://www.anpedesign.org.br/>. Access in: 15 mar. 2008.

[5] E. R. Souza, S. F. Freitas, Usabilidade do sistema Dosvox: entrevista com os desenvolvedores do sistema. In: Proceedings of USIHC 2008. São Luís, MA: NEPP UFMA, 2008.
[6] E. R. Souza, S. F. Freitas, Usabilidade do sistema Dosvox: estudo com cegos especialistas em acessibilidade. In: Proceedings of ABERGO 2008. Porto Seguro, BA, 2008.

[7] DRC - Disability Rights Commission. The Web access and inclusion for disabled people: a formal investigation conducted by the Disability Rights Commission, London. TSO, 2004.

[8] J. Nielsen; K. P. Coyne, Beyond ALT Text: Making the Web Easy to Use for Users with Disabilities. Fremont, California: Nielsen Norman Group, 2001.

[9] UN - United Nations. United Nations Global Audit of Web Accessibility. Online. Available in: <http://www.un.org/esa/ socdev/enable/documents/fnomensarep.pdf $>$. Access in: 22 apr. 2008

[10]J. Nielsen. Enhancing the explanatory power of usability heuristics. Proc. ACM CHI'94 Conf., Boston, MA, April 2428), 152-158, 1994. 